\title{
CONFRONTAÇÃO E CORDIALIDADE: ELEMENTOS PARA UMA COMPARAÇÃO ENTRE OS PENSAMENTOS AUTORITÁRIOS DE CARL SCHMITT E FRANCISCO CAMPOS
}

\author{
CONFRONTATION AND CORDIALITY: NOTES ON THE \\ AUTHORITARIAN THOUGHTS OF CARL SCHMITT AND \\ FRANCISCO CAMPOS
}

DOI: http://dx.doi.org/10.15448/2178-3748.2015.2.19686

\author{
Vinícius Liebel \\ Professor colaborador - PPGH PUCRS \\ v_liebel@yahoo.de
}

\begin{abstract}
RESUMO: Propõe-se no presente artigo uma reflexão acerca dos elementos centrais presentes no bojo do pensamento autoritário de direita que se desenvolve entre as décadas de 1920 e 1930 . Focado nos escritos de Carl Schmitt (Alemanha) e Francisco Campos (Brasil), o paper se pretende uma peça comparativa entre os dois, membros que são de uma elite intelectual que acabaria por forjar a estrutura jurídico-ideológica do Estado Novo e do Estado Nazista. As análises aqui propostas serão feitas em uma constante justaposição das ideias da matriz europeia, especialmente com os escritos schmittianos O Conceito do Político e Teologia Política, com aquelas que resultaram na obra principal de Campos no período,O Estado Nacional. Tomando os escritos de Carl Schmitt em comparação com os de Francisco Campos, dois juristas que atuaram em primeiro plano no campo dos debates políticos em seus países e que foram decisivos na busca por legitimação das ditaduras que os marcaram, as reflexões aqui propostas buscam verificar as sincronias e os pontos de divergência entre as estruturas teóricas de ambos os autores, resultando em uma caracterização global e qualitativa de seus pensamentos.
\end{abstract}

PALAVRAS-CHAVE: Autoritarismo. Francisco Campos. Carl Schmitt. Nazismo. Ditadura.

\begin{abstract}
It's proposed in this article a reflection on the central elements present in the authoritarian rightwing thinking developed between the 1920s and the 1930s. Focusing on the writings of Carl Schmitt (Germany) and Francisco Campos (Brazil), the paper is a comparative piece between their works, as they were members of an intellectual elite that would eventually forge the legal and ideological structure of the Estado Novo and the Nazi State. The here proposed analysis is a constant juxtaposition of the ideas from the European matrix, especially the Schmittianwritings The Concept of the Political and Political Theology, with those that resulted in Campos main work, The National State. Taking the writings of Carl Schmitt compared with those of Francisco Campos, two jurists who acted in the foreground of political debates in their countries and were decisive in the search for legitimacy to the dictatorships that were stablished, the reflections proposed here seek to verify the synchronicities and the points of divergence between the theoretical frameworks of both authors, resulting in a comprehensive and qualitative characterization of their thoughts.
\end{abstract}

KEYWORDS: Authoritarianism. Francisco Campos. Carl Schmitt. Nazism. Dictatorship.

Escrever, defender e pensar o Autoritarismo, ou o Estado Autoritário, nas turbulentas décadas de 1920 e 1930, não eram atos percebidos como uma excentricidade ou uma manifestação especialmente nefasta de negação da política e das liberdades individuais e 
coletivas. O que se vivenciava então era uma constante busca, por meio de tentativas, reflexões e teorizações, de um novo modelo político e estatal, um que desse conta da crise institucional, econômica e política que parecia abraçar, de forma avassaladora, todo o Ocidente. A percepção mais ou menos compartilhada por esses autores é de que não só o Liberalismo econômico mostrava seu desgaste, mas também o Liberalismo político e o próprio sistema democrático. $\mathrm{Na}$ tentativa de contenção das ideologias extremistas, especialmente as de esquerda, de institucionalização de uma ordem social e de retomada do desenvolvimento econômico que tais autores se guiavam.

Em meio a essa conjuntura, as diversas realidades nacionais se interpõem, fazendo perceber as aproximações e as peculiaridades de cada sociedade. A onda autoritária que avança no pós-guerra encontra impulso nos mais diversos pontos, nas mais diferentes realidades. E se não encontram suportes firmes em democracias mais consolidadas, as ideias autoritárias ainda têm um terreno fecundo em muitos países, inclusive alguns que podiam possuir um sistema democrático, mas careciam de uma cultura democrática plenamente desenvolvida (lembrando que, como Huntington (1991) afirma, os países que adotavam um sistema democrático chegaram ao número de 29 na primeira onda democrática, até 1922, para ter esse número diminuído para 12 no contra-fluxo democrático, até 1942). A queda no número de países democráticos se deve a uma conjunção de fatores globais e nacionais, mas deve muito de seu efeito ao surgimento dessa onda autoritária, responsável pela queda da confiança na Democracia, em alguns casos, e em outros, pelos avanços militares de ditaduras recentes.

Nesse ambiente, não são poucos os pensadores que tenderão ao autoritarismo quando analisam as alternativas para as crises políticas, econômicas e institucionais que são deflagradas no pós-guerra. Mas ainda que alguns desses autores sejam mais influentes e difundidos que outros, as especificidades nacionais são por demais relevantes nos resultados finais de suas reflexões. É pensando nessas especificidades que se propõe, com este paper, traçar um paralelo entre os escritos e as ideias de dois autores bastante representativos dessa onda autoritária, mas frutos de contextos completamente distintos: Francisco Campos, no Brasil, e Carl Schmitt, na Alemanha. Opera-se aqui sob uma perspectiva de análise de suas obras intelectuais, mas sem perder de foco não só os diferentes níveis de sentido de seus discursos, mas também a projeção de suas obras em suas comunidades de sentido específicas, em termos de Standortgebundenheiten, como apregoado pela Sociologia do Conhecimento (MANNHEIM, 1964, 1980, 1984). Nesse sentido, as análises comparativas efetuadas em sincronia e voltadas a temas delimitados e conjuntos proporcionará uma visão privilegiada e 
fluida dos pensamentos dos dois autores e dos sentidos próprios que desenvolvem. $\mathrm{Na}$ aproximação e comparação entre os dois pensadores e suas obras, objetiva-se apreender detalhes próprios de seus pensamentos, bem como uma linha comum que os aproxime e os comporte em um mesmo legado político e teórico de matiz autoritário.

As razões para a escolha desses dois personagens estão nas semelhanças biográficas e perceptivas que os aproximam. Trata-se de dois juristas, preocupados, portanto, com aspectos estruturais do político e com os elementos jurídicos que os delimitam. É sintomático, por exemplo, o fato de que ambos, ainda em meados da década de 20, estivessem pensando o dispositivo do estado de sítio ou de exceção: Francisco Campos em sua atuação junto ao Congresso Brasileiro (CAMPOS, 1979) e Carl Schmitt em seus estudos acadêmicos (SCHMITT, 1922). Mais reveladora ainda é a importância e a proeminência que os dois autores atingem com a gradual virada autoritária na política de seus países. Com a denúncia do forjado Plano Cohen e a instituição do Estado Novo, Francisco Campos consolida sua posição de ministro de Estado à frente da pasta do Ministério da Justiça e redige a "Polaca", a Carta Constitucional de 1937, que, se não entra oficialmente em vigor, garante os parâmetros pelos quais se guiará o governo ditatorial de Getúlio Vargas. Já Carl Schmitt, que chega em 1933 como um dos principais teóricos juristas da Alemanha, pavimentou com seus conceitos e digressões o caminho para a queda da República de Weimar, tornando-se já em novembro de 1933 (MASCHKE, 1980, p. 205), após uma filiação feita às pressas no NSDAP, o presidente da NS-Juristenbundes der Hochschullehrer, organização dos acadêmicos juristas ligados ao partido nazista. Tornou-se também, nos meses seguintes, diretor de importantes revistas acadêmicas, aumentando sua influência sobre o cenário acadêmico alemão. Sua filiação ao partido apenas quando da ascensão de Hitler, entre os Märzgefallene, ou seja, entre aqueles que esperaram uma definição do cenário político alemão para se registrarem no NSDAP (WEIGEL, 2009, p. 91-109), acabou por lançar dúvidas quanto à sua sinceridade partidária. Em 1936, em um artigo anônimo na revista da SS Das schwarzeKorps, Schmitt foi acusado de oportunismo e criticado por seu catolicismo militante. Foi então destituído das posições de liderança nas associações acadêmicas de que fazia parte, mas manteve sua cadeira na Universidade de Berlim, exercendo uma influência que seria primordial para a sobrevivência de sua obra no pós-guerra. Esse distanciamento nominal da alta cúpula nazista não apaga, claro, o papel que Schmitt teve no desenvolvimento de um pensamento autoritário que auxiliou na aceitação e na justificação do movimento totalitário que daria lugar ao Estado Hitlerista. 
A intenção aqui é justamente perceber, a partir de uma perspectiva comparativa, de que forma as ações e pensamentos desses dois juristas colaboram na construção ou reconstrução de uma cultura política de matiz autoritária em seus países. Ou seja, qual a contribuição desses autores na difusão de valores e de percepções políticas (MOTTA, 2014, p. 21), suas contribuições para a formação de uma visão de mundo que abrace a causa autoritária e que se sustente em um imaginário essencialmente antidemocrático ou antiliberal. Não se trata, portanto, de simplesmente retraçar as discussões conceituais e, especialmente adentrar nas tecnicalidades jurídicas de suas obras, mas sim elencar os conceitos e os esboços teóricos que esses autores apresentam e que se relacionam de forma mais íntima com as discussões e percepções políticas de seu período. Em suma, trata-se de apresentar a política a partir da ótica de Carl Schmitt e Francisco Campos, apontando, aí sim, elementos de interesse para o estudo de sua época. Para tanto, as reflexões a seguir tomam como elementos primários as obras O Estado Nacional (CAMPOS, 2001), de Francisco Campos, e Teologia Política (SCHMITT, 2005) e O Conceito de Político (SCHMITT, 2008a), de Carl Schmitt.

\section{O POLÍTICO ENTRE A RACIONALIDADE E A EMOTIVIDADE}

Tendo ambos os autores um olhar que pode ser classificado como realista sobre o campo da política, não surpreende o grau de negativismo de ambos em relação ao indivíduo. Profundamente marcado por suas leituras de Hobbes, Schmitt parte da concepção hobbesiana de estado de natureza para chegar em sua conclusão mais célebre: a de que o político é o campo de determinação e de ação baseadas na dicotomia amigo/inimigo. Essa distinção seria a força motriz da ação política, voltada para o bem-estar de uma unidade. Dessa forma, ela pode operar tanto no plano interno quanto no plano externo. É tomada p.e. como uma justificativa teórica para a eliminação dos inimigos e dos corpos estranhos à Volksgemeinschaft na Alemanha nazista, notadamente os judeus, mas também para antecipar e justificar a guerra que se aproximava em 1939. Em texto de 1938 (SCHMITT, 2008b), Schmitt conjuga suas ideias sobre a sociedade de massas, o estado de exceção e a dicotomia amigo/inimigo com a imagem então bastante difundida da guerra total. A ideia central é a de que a sociedade de massas propicia o ambiente para o desenvolvimento da guerra total, onde a guerra ultrapassa o caráter meramente militar do conflito, abrangendo em si outras modalidades, como a guerra econômica, a guerra propagandística, etc. O argumento que 
Schmitt apresentava é de que os anos 1920 e 30 foram uma espécie de zona cinzenta, um período intermediário entre a guerra e a paz, na qual os inimigos estavam claramente determinados, configurando-se uma antessala para o conflito armado. Assim, ainda que o Estado hitlerista tenha agido por uma unidade nacional, eliminando os eleitos inimigos e impondo uma ordem interna, afastando o pesadelo hobbesiano da guerra civil, o estado de exceção se configurava pelo ambiente de franca hostilidade entre as potências externas, cabendo ao soberano, ou melhor, ao Führer, a prerrogativa de levar o conflito para o âmbito militar. A guerra "em ação" dependia das iniciativas militares, mas a guerra "como estado" já se observava. O político, para Schmitt, se apresenta assim como um campo essencialmente de confronto, que pode ocorrer em quaisquer domínios. Isso não significa, claro, que o enfrentamento seja uma necessidade constante; mesmo em Schmitt pode-se vislumbrar um espaço para o diálogo e para a negociação. O aspecto principal, entretanto, é o reconhecimento dos inimigos e a consciência da potencial confrontação.

Já para Campos, a política é um campo de disputa de interesses e de decisões. Em suas reflexões, o jurista mineiro argumentava, ainda em 1935, que o modelo representativo do Liberalismo atenuava essa situação ao reduzir sua escala, tentando conter as paixões envolvidas no processo político através da racionalidade do Parlamento. Entretanto, a ascensão das massas ao campo da política teria tornado insustentável essa “dissimulação". É nesse sentido que Campos vê uma nova era na qual a política seria baseada nas paixões das massas, ou, em seu vocabulário: seguindo o "primado do irracional”, a política deveria se guiar pelo "primado do inconsciente" (CAMPOS, 2001, p. 19). As massas, assim, deveriam se unir em torno de mitos e de imagens unificadoras, dentre as quais se destacaria a figura do César, encarnando o princípio da liderança, em direção a uma cultura unificada e voltada ao interesse coletivo. Nesse sentido, as liberdades individuais deveriam ser revistas em favor da união, da ordem e da coletividade. É um princípio emotivo que norteia o ambiente do campo político em Francisco Campos, uma emotividade que gera, por si só, o sentimento de unidade, identidade e pertença, propulsores primários da ação.

De fato, a ideia da unidade permeia as reflexões dos dois autores. Para ambos, a política de massas elevou os ânimos nacionais, possibilitando a observação de um processo que evidenciaria a "vontade geral da nação", colocando as massas em primeiro plano na política e minimizando o caráter representativo dos Parlamentos, definidos pelo alemão como a casa da "classe discutidora", afeita à indecisão e ao conchavo. A representação que realmente interessa tanto para Campos quanto para Schmitt é aquela estabelecida entre as massas, ou melhor, o povo e o soberano, o líder que espelharia a vontade geral, em um retorno 
a uma relação de encantamento do poder público, evidência de um tempo em que a autoridade já fora sacra e estava apta a realmente agir quando necessário.

\section{FONTE DA AUTORIDADE E O CONCEITO DE SOBERANIA}

Para Schmitt, é o Leviatã, o Estado, que possui a prerrogativa do poder soberano. Partindo do pressuposto de que a normalidade está posta com as leis e a ordem, é na anormalidade, ou seja, na exceção, que o soberano agiria, estando mesmo essa sua ação "fora da ordem" coberta pela legalidade do estado de sítio ou exceção. Os atos de exceção estariam assim configurados como atos fora da norma constitucional, mas ao mesmo tempo, previstos pela Constituição. Essa dupla caracterização garante uma justificativa teórica para o constitucionalismo antiliberal de Schmitt, e abre espaço ainda para o "salto de fé" da representação do soberano. Sendo ele o reflexo dos anseios e temores da nação, é natural que a ele caiba a decisão sobre a exceção, não apenas no sentido de decidir o que fazer durante a exceção mas também de decidir o que é a exceção ${ }^{1}$.

Oportunidades para apontar a exceção, como um breve olhar sobre a Alemanha do período demonstra, não faltavam. A inflação galopante, as milícias e as organizações paramilitares, batalhas campais ideológicas e as denúncias paranoicas, por todos os lados, de inimigos da nação, seja em discursos, nas mesas dos Biergärten ou nas páginas de jornais como o Der Stürmer, tudo isso criava um clima de decadência e de emergência. O autor Hans Meisel, escrevendo para o jornal berlinense VossischeZeitung em outubro de 1930, dizia presenciar "a auto-destruição da burguesia, o suicídio psicológico de toda uma classe", e acusava: "Grande parte da juventude de classe média sequer pensa mais em termos burgueses, mas apenas como marxistas ou fascistas" (MEISEL Apud BROSZAT, 1987, p. 16). Sobre o mesmo tema, o sociólogo Hans vonEckart escreveu, em 20 de novembro, que "o desejo das massas de se ocuparem, de participarem, de se envolverem, não pode mais ser ignorado. Não se trata mais dos líderes serem bem-sucedidos, como eles gostam de afirmar, mas das massas empurrando para toda direção que lhes seja dada a oportunidade" (ECKART Apud BROSZAT, 1987, p. 17).

\footnotetext{
1“Souveränist, werüber den Ausnahmezustandentscheidet.” (SCHMITT, 1922, p. 1)
} 
Esses testemunhos dão mostras da convulsão do contexto, da falta de unidade nacional, da decadência dos chamados valores burgueses alemães e das disputas internas que causavam a constatação em Schmitt da necessidade de um líder soberano que mantivesse a unidade e que protegesse a ordem. Para ele, era a hora do surgimento desse líder, alguém que desse conta desse "estado permanente de exceção", como descrito por Walter Benjamin (2013, p. 13). Seguindo reflexão de Habermas, evidencia-se em Schmitt que

O Estado é a guerra civil continuamente impedida. Sua dinâmica constitui-se na repressão da revolta, na sujeição continuada de um caos, instalado na natureza má dos indivíduos. Estes insistem em sua autonomia e pereceriam no sobressalto de sua emancipação, se não fossem salvos pela facticidade de um poder que domina qualquer outro poder. (HABERMAS, 2008, p. viii)

O que faz o soberano em tempos de normalidade? Ele dorme, diria George Schwab (1970), apenas para acordar em tempos de exceção.

O soberano, para Campos, também detém um caráter eminentemente decisório. Mas ele não se caracterizaria pelo excepcional, e sim pelo normativo. A decisão política em Campos se desloca do processo parlamentar infrutífero para o da vontade encarnada pelo Executivo. A soberania, para Campos, está no corpo onde a vontade do povo se manifesta. É assim que ele percebe a dinâmica parlamentar como um campo impossível de manifestação da soberania, uma vez que a sociedade de massas traria consigo a violência e a agressividade dos embates ideológicos (às quais o Estado deveria se contrapor com repressão). A grande mácula do sistema, segundo Campos, não reside, entretanto, na pura diferença de opiniões e de interesses. Essas características são naturais e inerentes a qualquer agrupamento políticosocial. A mácula está na incapacidade do sistema parlamentar em contornar ou em orientar essas diferenças. O Executivo, ou seja, o presidente, dotado de poderes autoritários ditatoriais e guiado pela vontade geral que ele encarna, age como juiz e executor das opiniões e dos interesses que lhe são apresentados pelos órgãos coletivos de caráter técnico e popular, em especial pelas corporações e conselhos nacionais.

Duas considerações são particularmente interessantes nesse aspecto. A primeira é a diferença entre as justificativas para o poder soberano ditatorial em Campos e em Schmitt. Para o alemão, tratava-se de um retorno ao princípio teológico do político, pois a força dos

\footnotetext{
2 "A tradição dos oprimidos ensina-nos que o "estado de exceção" em que vivemos é a regra. Temos que chegar a um conceito de história que corresponda a essa ideia. Só então se perfilará diante dos nossos olhos, como nossa tarefa, a necessidade de provocar o verdadeiro estado de exceção; e assim a nossa posição na luta contra o fascismo melhorará." (BENJAMIN, Walter; 2013, p. 13).
} 
conceitos e dos elementos políticos teria se perdido com a racionalização do político ocorrida nos últimos séculos ${ }^{3}$. Dessa forma, com um retorno ao encantamento na política, o salto de fé que garante ao soberano sua autoridade, as decisões necessárias para a sobrevivência no estado de exceção seriam finalmente possibilitadas. Já para Campos, ainda que o Estado Novo tenha se erigido no mesmo princípio de exceção, ele representaria uma tentativa de normatização, um poder moderador e regulador dos interesses nacionais que serviria para trazer o equilíbrio à "democracia autoritária” defendida pelo jurista mineiro. Nesse ponto, Campos se diferia de outros pensadores autoritários do período, os quais, por sua vez, aproximavam-se mais de Schmitt. "Para estes, a finalidade de um regime político, isto é, a concentração da autoridade e a realização da ordem, é o que importava. Diferentemente desses autores, em Campos (...) a legitimação democrática antiliberal - plebiscitária ou corporativa - aliava-se à necessidade de uma recomposição jurídica e estrutural do Estado" (SANTOS, 2007, p. 285). É justamente essa busca por uma recomposição estrutural que aponta para a vocação normativa das ideias campistas, demonstrando uma ambiguidade inerente de seu pensamento: na busca por uma democracia normativa, o dispositivo da ditadura, ou melhor, da "democracia autoritária", é acionado. Isso não impedia, é claro, que a discussão sobre a aura da autoridade fosse levantada por Campos: o presidente, enquanto espelho de sua sociedade, possuidor de uma sintonia única com o povo, e referendado, quando necessário, através de plebiscito, teria a autoridade necessária para exercer sua soberania. Sua vontade, traduzida como vontade do povo, serviria de guia para as decisões técnicas e políticas necessárias, apresentadas, nos termos dessa democracia autoritária, pelos aparelhos técnicos elitistas do Estado e pela prerrogativa legislativa do presidente.

A segunda consideração a ser levantada é a tentativa de Campos, já quando da redação da Constituição de 1937, de reconstrução da memória da Revolução de 30. Em suas palavras, a urgência que a consciência coletiva impunha às reformas políticas de caráter autoritário já seriam os motivadores de todo o movimento revolucionário, e a demora do preenchimento desses anseios é devida justamente à política partidária e a seus freios democráticos. Os acordos políticos feitos com os mais diversos movimentos quando da eclosão da revolução, as manobras políticas e a própria dinâmica pessoal de Vargas são varridas da memória em prol de uma mitificação dos heróis revolucionários. Dessa forma legitimava-se todo o movimento

\footnotetext{
${ }^{3}$ Tem aqui um papel relevante em Schmitt a influência de Weber e suas ideias acerca do desencantamento do mundo, que seria, em linhas gerais, a perda do não-racional no campo do político, dando lugar às técnicas, ao formalismo e à burocracia. O campo do formalismo e da burocracia é identificado com as políticas do Parlamento, que minam a própria política, entendida como personalização, assim como a autoridade passa a ser uma questão de pura tecnicalidade. É contra essa tecnicalidade, pelo retorno de uma aura às instituições e personificações do político, que Schmitt se referirá ao defender sua teologia política.
} 
revolucionário, os anos de exceção e luta contra os adversários e a nova realidade do Estado Novo como um marco de uma nova era, uma nova oportunidade de reinício para o país. A mitologia que envolve essa construção da memória está ligada a duas imagens de apelo muito forte no campo das mentalidades: a da era de ouro, localizada, no caso do Estado Novo, no futuro imediato, e a da unidade, resultando em um arcabouço imagético-discursivo que justifica, explica e mobiliza sua visão de mundo autoritária, bem como purifica, de certa forma, esse novo começo (GIRARDET, 1986, p. 97 et seq.). E essa estrutura mitológica está, por sua vez, estreitamente ligada à concepção de política de Campos. Se a política é tomada por Campos como o lugar da vontade ou o suposto palco das decisões, ela é apresentada em dois momentos distintos: o da inércia e da podridão do "caudilhismo provinciano"(CAMPOS, 2001, p. 43), por um lado, e o novo tempo, o da tradução da significação coletiva da nação e do decisionismo. Não à toa, em entrevista no ano de 1939, ao expressar os feitos de quase dois anos de Estado Novo, dentre os quais se destacavam o Código Civil e os aparatos de repressão que o balizavam, Campos tergiversa:

Novidades políticas? Mas o que eu disse já não é política? É política dotar o Brasil de leis claras e justas. É política promover a boa distribuição de justiça. É política aperfeiçoar a administração. É política realizar obras produtivas. É política aparelhar as forças armadas. É política fomentar a harmonia nacional. É política desenvolver o espírito da unidade da Pátria. Tudo isto é política, a melhor política, e essa política é a que vêm praticando todos os órgãos do governo, sob a clara direção do Presidente Getúlio Vargas. (CAMPOS, 2001, p. 160)

Outro ponto interessante é a relação da ideia de soberania com o Estado corporativo ${ }^{4}$, relação da qual se infere que o soberano, no uso de seus atributos decisórios, detém a premissa da arbitragem diante dos dilemas nos rumos da economia nacional. Nas palavras do próprio Campos, "a descentralização pelas corporações não implica, pois, a indiferença do Estado pela economia. Cada corporação representa um setor da economia nacional. Só, porém, o estado, que não tem interesse particularista, está em condições de representar o interesse nacional e de exercer, portanto, a arbitragem entre os interesses de categorias ou de setores" (CAMPOS, 2001, p. 64). A retórica do corporativismo permitia ao Estado Novo, como aponta Alcir Lenharo (1986, p. 27), formular uma imagem híbrida de si mesmo que se mostrava mais palatável a uma nova elite industrial e a uma classe média urbana em

\footnotetext{
${ }^{4}$ Neste aspecto ressoa na obra de Francisco Campos a influência de Oliveira Vianna, que defendia a maior legitimidade da representação corporativa ou classista quando em comparação com a representação parlamentar.
} 
desenvolvimento. Nessa imagem, o Estado Novo diferenciava o Liberalismo político do econômico (do qual se afirmava, ao menos parcialmente, adepto), a Democracia liberal da Democracia autoritária (centrada na figura do líder, que governava com base no apoio popular e do inconsciente coletivo). Nessa concepção de Estado, a livre iniciativa, os "empreendedores" teriam papel central na sustentação da economia nacional, enquanto sua ordenação seria centrada nas mãos do governante. No jogo de representações imaginárias (CASTORIADIS, 1986), o Estado Novo abraça a ideia de Democracia autoritária, o que apresenta, mais do que uma orientação prática, uma forma de concessão discursiva e conceitual do aparato autoritário.

Esse princípio da representação corporativista na base de uma Democracia autoritária revela uma diferença conceitual sutil, mas determinante, entre as ideias de Campos e Schmitt. Para o alemão, a solução para a crise política na sociedade de massas está não na representação (seja ela parlamentar ou corporativa), um conceito que imediatamente secciona o corpo social e impõe uma hierarquia política que mina a igualdade radical que deveria ser imanente no sistema democrático (BENJAMIN, Cássio Corrêa, 2008, p. 423), mas sim na identidade, um conceito que favorece a unidade e a centralização das decisões. Essa forma de representação não cabe em sua teoria, ao contrário da representação da unidade. $\mathrm{O}$ que Schmitt defende é uma ditadura, sem o artifício, prático ou retórico, das representações sectárias. Nesse sentido, a fórmula é simples ${ }^{5}$ : quanto mais identidade, menos representação; quanto mais representação, menos identidade (SCHMITT, 2003). A representação seccional age, assim, de maneira inversa à representação unitária, quando a unidade da nação pode ser representada na figura do rei, do César ou do Führer.

\section{SENTIDO HISTÓRICO EM SCHMITT E CAMPOS}

Diante desse panorama sobre alguns pontos essenciais das obras de Francisco Campos e Carl Schmitt, podemos vislumbrar a possibilidade de encontrar, em suas obras, uma concepção de tempo histórico, para além da visão acerca do passado, já evidenciada. Em outras palavras, buscamos aqui um sentido histórico em seus textos, dando conta de uma

\footnotetext{
${ }^{5}$ Isso não inclui, claro, a ideia de representação da unidade da nação, um conceito que só é possível de operar dentro dos planos da representação. No exemplo de Schmitt, uma praça com todos os cidadãos ativos de um povo não formam a unidade do povo, mas representam essa unidade. A unidade, de fato, transcende o espaço e o tempo, e por isso só pode ser representada.
} 
feição mais ampla acerca dessas culturas autoritárias das quais os dois autores são frutos, ao mesmo tempo em que formadores e definidores.

Sobre esse tema, encontramos em Schmitt sua base na própria definição amigo/inimigo, que, como princípio de identidade, é também uma definição do tipo nós/eles. É na unidade desse grupo "nós" que Schmitt visualizará o papel decisório do soberano, voltado sempre para o reconhecimento e potencial confronto. É o conflito que marca a história dessas coletividades, desde sua origem até o futuro indeterminado. Não há, entretanto, um princípio necessariamente teleológico para esse ordenamento histórico, ou seja, para Schmitt, a definição de inimigo não leva necessariamente a uma sucessão de confrontos até o surgimento do grande vitorioso da história. Ao mesmo tempo, seu realismo se mostra bastante combativo, levando seu leitor a antever um estado permanente de tensão entre os atores por toda a história, sendo a única possibilidade de suspensão desse estado a completa hegemonia de um Estado totalitário que não encontre freios ou barreiras para seu desenvolvimento. Para Schmitt, a harmonia só pode ser alcançada pelo domínio hegemônico, e a história seria uma inevitável sobreposição de confrontos e de violências. O que se vislumbra em sua obra é que o completo domínio do normativismo (mundo das leis, constitucionais ou gerais) e do institucionalismo (mundo das instituições e da burocracia) enquanto forças motrizes no campo do político significaria o fim da história, o fim das ações propriamente humanas ligadas ao decisionismo (este sim, o mundo dos homens sobre as leis e sobre as instituições).

Em Schmitt, a busca é pela renovação dessa dinâmica histórica de confrontação e identificação coletiva, uma vez que a própria história recente europeia teria operado em favor de uma individualização da sociedade e do esvaziamento do político, ou melhor, da neutralização e da despolitização (SCHMITT, 2008a, p. 96). Decorre dessa constatação um conceito histórico generalista e mecanicista, no qual um conceito geral ou um campo social determina o pathos e o Zeitgeist, e em torno deles o progresso da história é observado, em busca sempre de uma esfera neutra - na qual o confronto eventualmente assumirá, também, seu papel determinante, obrigando a sociedade, enfim, a buscar um novo campo de neutralidade.

\footnotetext{
A humanidade europeia sempre migra de uma área de luta para uma área neutra, a área neutra recém-conquistada sempre se torna, imediatamente, uma área de luta outra vez, tornando necessária a procura por novas esferas neutras. Mesmo o cientificismo natural não foi capaz de instituir a paz. As guerras de religião se transformaram nas guerras nacionais do século XIX, determinadas meio ainda culturalmente, meio já economicamente, se
} 
convertendo, por fim, simplesmente nas guerras econômicas. (SCHMITT, 2008a, p. 97)

Para o autor alemão, a crença novecentista de se ter encontrado na técnica um campo neutro definitivo seria apenas um prólogo para o novo capítulo da confrontação: a técnica, enquanto mero meio, não poderia se constituir em um campo, e seu destino estaria apenas em conceber novos meios de empreendimento da confrontação.

Decorre dessas considerações que o conceito do político em Schmitt, ainda que não implique a completa politização de todas as esferas da vida, tem em si o princípio da totalização. Quando alguns intérpretes de Schmitt, como Bercovici, apontam para o fato de que "Schmitt deseja garantir a autonomia das esferas não estatais" e que "Só um Estado forte pode se retirar dessas esferas (sendo) o Estado neutro um Estado forte, pois se separa da economia e da sociedade civil”" (BERCOVICI, 2013, p. 94), estão, na realidade, pensando em propostas práticas e imediatas do autor em favor de uma elite industrial alemã e desconsideram que essas esferas podem, em casos emergenciais, também ser apreendidas pelo político. O Estado mais forte é aquele que não tem inimigos porque os dominou, e a economia é um campo tão apto quanto qualquer outro a se tornar um campo de atrito e causa da exceção.

Em Campos, a preocupação com a unidade também é central, e, com ela, a busca pelo reencantamento da política, no sentido de reconstruir a aura da autoridade perante a nação. $\mathrm{O}$ novo estágio histórico, no qual as massas ascendem ao primeiro plano da política, evidencia ainda mais o caráter premente da autoridade enquanto guia e protetora da ordem nacional. Essa ordem, entretanto, na visão de Campos, deve traduzir os anseios das massas, em uma releitura da democracia. As liberdades devem ser revistas e a participação, efetuada através de mecanismos tutelados, se restringe a um grupo de especialistas, uma elite formada para o aconselhamento do presidente. Mas essas novas estruturas são pensadas para inserir o país em uma nova realidade, a realidade dos grandes avanços técnicos e do movimento das massas, e é nesse movimento, que é dinâmico e intempestivo, que as ações soberanas se sustentarão. É na vontade do soberano que a irracionalidade das massas receberá uma ordenação, e os instrumentos primeiros a serem utilizados, tanto na unificação das massas quanto em sua instrumentalização, seriam os mitos. O mito nacional, a unidade, o salvador, a era de ouro; todas essas imagens são empregadas pela propaganda e pela educação do Estado moderno de massas com a finalidade de orientar a sociedade rumo à ordem e a um bem comum. Nesse aspecto, Campos defende uma certa ordenação que a ditadura traria a esse uso dos mitos, 
evitando que eles extrapolem o campo do controle do centro de vontade e se submetendo a ele. O interessante, aqui, é que esses esforços não se fazem em nome de uma busca sistemática de uma ordem amigo/inimigo visando o confronto ou a sua possibilidade latente como em Schmitt, mas sim em nome da neutralização dos confrontos ${ }^{6}$. Nas palavras de Campos, "o clima de benignidade, contrário a todos os extremos, o equilíbrio, a modéstia, a medida, as virtudes da serenidade e da compreensão" (CAMPOS, 2001, p. 206), esses seriam os valores que guiariam a fundação de um Estado Novo. A história, em Campos, é uma incógnita, mas cabe ao Estado se adaptar, da melhor forma possível, "para o que der e vier".

\section{CONCLUSÃO}

Percebe-se, com a análise desses elementos aqui expostos, uma orientação específica das culturas políticas nas quais os autores estão inseridos e que são, não apenas frutos, mas também influenciadores. Os argumentos, as imagens evocadas e a organização de seus pensamentos apontam especificidades que distinguem os contextos, as realidades nacionais, enfim, os habitus políticos brasileiro e alemão naquele período, na medida em que não apenas são parte da construção argumentativa e tomam parte nas discussões públicas do período, como também são utilizadas na sustentação teórica e retórica dos regimes que ajudam a erigir.

As argumentações de Schmitt, nesse sentido, apontam para uma facilidade e uma receptividade maior, na República de Weimar, de uma solução autoritária violenta para a crise enfrentada pelo Estado. A ditadura não era percebida como uma afronta à cultura política nacional - pelo contrário, a república democrática era percebida como uma imposição estrangeira por parte da população - ou às liberdades individuais, e a história recente corroborava e ilustrava a visão de Schmitt sobre a centralidade da definição amigo/inimigo e do decisionismo na política nacional, seja na dinâmica bismarckiana da Realpolitik e o reconhecimento da França como inimigo a ser isolado, seja no processo de reunificação em torno da Prússia militarista ou mesmo na existência de uma figura patriarcal no centro decisório da nação, como fora, por exemplo, a figura simbólica e idealizada de Frederico II. É também determinante que toda a dinâmica política da Alemanha moderna tenha se erigido sobre mecanismos de exclusão e de inclusão voltados ao conservadorismo, "instituindo um

\footnotetext{
${ }^{6}$ Ao basear sua argumentação pela democracia autoritária na técnica, no decisionismo frente aos desafios cada vez maiores que a modernidade impõe, não se abre espaços, no Estado campista, para o princípio schmittiano da confrontação. A técnica é neutra, assim como a vivência do Estado também acaba por sê-lo.
} 
parlamento sem poder, partidos políticos sem acesso às responsabilidades governamentais e eleições cujos resultados não determinavam a composição do governo" (KOLINSKY; WILL, 1998, p. 12). São elementos e imagens políticas e sociais que estão no plano de fundo da argumentação de Schmitt, e também concorrem na recepção de sua retórica. A violência imanente ao processo de ação política em Schmitt não é reconhecida como uma afronta ou uma anormalidade política. É, antes, a própria natureza da política.

Em Campos, a retórica se volta para a solução de conflitos pelo seu contorno, e não através do embate ${ }^{7}$. Trata-se, claro, de artifício discursivo, uma vez que a própria ordem do Estado Novo é imposta e mantida pelo embate e pela violência repressiva, além do combate sistemático aos extremismos e partidarismos, dentre os quais se destacam Comunismo e o Integralismo, tidos como agentes primeiros da desestabilização da ordem e da unidade. Mas a imagem que ela gera, antes e após o estabelecimento do novo regime, é a da estabilidade amparada na neutralidade da técnica e na convivência neutra e pacífica, diferente, portanto, da imagem gerada pela retórica de Schmitt, do combate perene e da constante ordenação do mundo pela dicotomia amigo/inimigo, para a qual é eleita como artifício ideal a figura do judeu.

Em Schmitt, domina a retórica da confrontação, pois para o autor a "política e o Estado não podem ser neutros, porque a existência humana, o poder e o Direito não o são" (ALMEIDA FILHO, 2014, p. 38). Essa retórica do combate, em Campos, parece estar fora de lugar. A cultura que se revela não é a do embate, mas o da conciliação (MOTTA, 2013, p. 18), reforçando o mito do convívio edênico e o imaginário do brasileiro pacífico. É a cordialidade, acima de qualquer possível valor de confrontação, que domina os escritos de Campos. Ainda que a repressão e a perseguição a estrangeiros, comunistas, integralistas e outros elementos considerados nocivos ao Estado revelem uma ação belicosa, o discurso em Campos revela uma tentativa de apaziguamento ${ }^{8}$. O Estado Novo surge, assim, para abafar os

\footnotetext{
${ }^{7}$ Bolívar Lamounier aponta que a constituição de uma ideologia de Estado neste período, que teria em Francisco Campos um de seus ideólogos, responde a oito componentes básicos: "1)Predomínio do princípio 'estatal sobre o princípio de 'mercado'; 2) Visão orgânico-corporativa da sociedade; 3) Objetivismo tecnocrático; 4) Visão autoritária do conflito social; 5) Não organização da sociedade civil; 6) Não mobilização política; 7) Elitismo e voluntarismo como visão dos processos de mudança política; 8) O Leviatã benevolente.” (LAMOUNIER, 1985, p. 359).

${ }^{8}$ O Comunismo, que seria um candidato natural para uma distinção amigo/inimigo no pensamento de Campos, não é focado enquanto tal em seu discurso. Alguns motivos para tanto podem ser apontados, dentre os quais a sua definição do comunismo-marxismo como um resultado natural da degeneração do liberalismo (e a solução deste teria como consequência lógica a solução daquele), o foco primário do autor na reconstituição do Estado e na integração política ao redor da figura do chefe, bem como a sistemática e já em curso repressão contra os comunistas, desde 1935, razão do permanente estado de sítio nos anos de 35-37. Dessa forma, ainda que o anticomunismo seja um elemento forte na constituição e no imaginário brasileiro no período, em Campos ele
} 
conflitos que a decadência liberal, somada à ascensão das ideologias extremistas e das massas ao primeiro plano da política, teria trazido ao tradicionalmente pacífico povo brasileiro ${ }^{9}$, se voltando assim antes à desmobilização das massas do que à sua mobilização (SILVA, 2004, p. 67). O Estado Hitlerista, por sua vez, teria surgido para combater esses conflitos, bem como para estabelecer uma luta constante contra seus inimigos.

Em ambos os autores, entretanto, a vontade dos líderes se torna base para uma decisão justa e eficiente, assim como o desaparecimento do indivíduo ordinário frente à unidade do Estado (BOOKBINDER, 1981, p. 144) se torna uma condição necessária para o ordenamento nacional. É sempre ao bem da nação que essas imagens servem. Dessa forma, a análise comparativa dá pistas também para uma visão geral dos argumentos autoritários do período, pleno de condescendência para com as massas modernas e desconfiança quanto à sua capacidade decisória. É imperativo, assim, que elas sejam ordenadas, que a autoridade e a soberania inerente a seus líderes autoritários as guiem para uma unidade nacional, utilizando de sua força para a obtenção dos resultados que o mundo moderno requer. Isso se opera, portanto, graças à ascensão de uma visão da política enquanto campo da unidade, da irracionalidade, da decisão e da vontade, elementos que concorrem, necessariamente, pelo esvaziamento da concepção de política enquanto processo de debate e resoluções coletivas.

\section{REFERÊNCIAS}

ALMEIDA FILHO, Agassiz. 10 Lições sobre Carl Schmitt. Petrópolis: Editora Vozes, 2014

BENJAMIN, Cássio Corrêa. Schmitt e o Problema da Democracia - nostalgia da transcendência ou a representação como questão para a Democracia. In: Kriterion, Belo Horizonte, n. 118, dez. 2008, p. 417-441

BENJAMIN, Walter. Sobre o Conceito de História. In: BENJAMIN, Walter. O Anjo da História. Belo Horizonte: Autêntica, 2013.p. 7-20

BERCOVICI, Gilberto. Carl Schmitt e a Tentativa de uma Revolução Conservadora. In: ALMEIDA, J.; BADER, W. O Pensamento Alemão no século XX. vol. 1. São Paulo: Cosacnaif, 2013. p. 83-122.

perde espaço para o discurso da integração. E essa distinção é relevante porque ela revela a especificidade argumentativa da obra de Campos e seu papel na construção discursiva em torno da fundação do Estado Novo.

9 As estratégias de conciliacionismo na política brasileira tendem a ser mais eficientes quando a conciliação é feita entre as elites (RODRIGUES, 1965), dessa forma reforça-se a necessidade do estabelecimento de uma elite na composição do Estado Novo, de modo a acomodar os imperativos sectários ou de classes e promover o apaziguamento dos conflitos. É a esse intuito que o corporativismo e as políticas trabalhistas do Estado Novo se prestam. 
BOOKBINDER, Paul. Roots of Totalitarian Law: the early works of Carls Schmitt. Social Science, vol. 56, n. 3, 1981. p. 133-145.

BROSZAT, Martin. Hitler and the Collapse of Weimar Germany. Berg: Hamburg, 1987.

CAMPOS, Francisco. Sessão de 31 de Julho de 1924 da Câmara dos Deputados. In: CAMPOS, Francisco. Francisco Campos - Discursos Parlamentares. Brasília, Câmara dos Deputados, 1979.

2001.

O Estado Nacional: sua estrutura, seu conteúdo ideológico. Brasília: Senado Federal,

CASTORIADIS, Cornelius. A Instituição Imaginária da Sociedade. Rio de Janeiro: Paz e Terra, 1986.

GIRARDET, Raoul. Mytheset Mythologies Politiques. Paris: éditions Du Seuil, 1986.

HABERMAS, Jürgen. Liquidando os danos - os horrores da autonomia. Apresentação a SCHMITT, Carl. O Conceito do Político; Teoria do Partisan. Belo Horizonte: Del Rey, 2008. p. vii-xix.

HUNTINGTON, Samuel. The Third Wave: Democratization in the Late Twentieth Century. Norman: Univ. of Oklahoma Press, 1991.

KOLINSKY, Eva; WILL, Wilfred van der. In Search of German Culture: an introduction. In: KOLINSKY, E.; WILL, Wilfred (ed.). The Cambridge Companion to Modern German Culture. Cambridge: Cambridge University Press, 1998. p. 1-19.

LAMOUNIER, Bolívar. Formação de um pensamento político autoritário na Primeira República: uma interpretação. In: FAUSTO, Boris (org.). História Geral da Civilização Brasileira - o Brasil Republicano. vol. 9. Rio de Janeiro: Difei, 1985. p. 359.

LENHARO, Alcir. A Sacralização da Política. São Paulo: Papirus, 1986.

MANNHEIM, Karl. Wissenssoziologie- AuswahlausdemWerk. Berlin / Neuwied: Luchterhand, 1964. . Strukturen des Denkens. Frankfurt amMain : Suhrkamp, 1980.

Konservatismus. Frankfurt am Main : Suhrkamp, 1984.

MASCHKE, Günter. ImIrrgarten Carl Schmitts. In: CORINO, Karl (org.). Intellektuelleim Bann des Nationalsozialismus. Hamburg: Hoffmann und Campe, 1980. p. 205.

MOTTA, Rodrigo Patto Sá. Desafios e Possibilidades na Apropriação de Cultura Política pela Historiografia. In: MOTTA, Rodrigo Patto Sá (org.). Culturas Políticas na História - Novos Estudos. Belo Horizonte: Fino Traço, 2014. 13-38.

MOTTA, Rodrigo Patto Sá. Ruptura e Continuidade na Ditadura Brasileira. In: MOTTA, R. P. S.; ABREU, L. A. (org.). Autoritarismo e Cultura Política. Porto Alegre: Edipucrs, 2013. 9-32.

RODRIGUES, José Honório. Conciliação e Reforma no Brasil. Rio de Janeiro: Nova Fronteira, 1965.

SANTOS, Rogério Dultra dos. Francisco Campos e os Fundamentos do Constitucionalismo Antiliberal no Brasil. In: Dados - Revista de Ciências Sociais, Rio de Janeiro, vol. 50, n. 2, 2007, p. 281-323.

SCHMITT, Carl. PolitischeTheologie. Berlin: Dunker \&Humblot, 1922.

. Verfassungslehre. Berlin: Duncker\&Humblot, 2003. 
. Political Theology - Four Chapters on the Concept of Sovereignty. Chicago: University of Chicago Press, 2005.

. O Conceito do Político; Teoria do Partisan. Belo Horizonte: Del Rey, 2008a.

. Corolário II: Sobre a relação entre os conceitos de guerra e inimigo. In: SCHMITT,

Carl. O Conceito do Político; Teoria do Partisan. Belo Horizonte: Del Rey, 2008b. p. 110119.

SCHWAB, George. The Challenge of the Exception - An Introduction to the Political Ideas of Carl Schmitt between 1921 and 1936. Berlin: Duncker\&Humblot, 1970.

WEIGEL, Björn. "Märzgelallene" und AufnahmestoppimFrühjahr 1933 - Eine Studieüber den Opportunismus. In: BENZ, Wolfgang (org). Wiewurde man Parteigenosse? Frankfurt am Main: Fischer, 2009. p. 91-109. 